\title{
Shelf Life of Monovarietal Extra Virgin Olive Oils Cv. Arbequina and Coratina from Uruguay
}

\author{
Bruno A. Irigaray ${ }^{1}$, Natalia I. Martínez ${ }^{1}$, Camila Feller $^{1}$, Miguel Amarillo $^{1} \&$ Maria Antonia Grompone ${ }^{1}$ \\ ${ }^{1}$ Departamento de Ciencia y Tecnología de los Alimentos, Laboratorio de Grasas y Aceites, Facultad de Química, \\ Universidad de la República, Montevideo, Gral. Flores 2124, Uruguay \\ Correspondence: Bruno A. Irigaray, Departamento de Ciencia y Tecnología de los Alimentos, Laboratorio de \\ Grasas y Aceites, Facultad de Química, Universidad de la República, Montevideo, Gral. Flores 2124, Uruguay. \\ E-mail: mgrompon@fq.edu.uy
}

$\begin{array}{lc}\text { Received: July 13, } 2016 \quad \text { Accepted: August 4, } 2016 \quad \text { Online Published: September 19, } 2016 \\ \text { doi:10.5539/jfr.v5n5p88 } & \text { URL: http://dx.doi.org/10.5539/jfr.v5n5p88 }\end{array}$

\begin{abstract}
Two monovarietal extra virgin olive oils (Arbequina and Coratina), produced in Uruguay, were studied over a period of 12 months storage in amber bottles at $30^{\circ} \mathrm{C}$. Peroxide index, $\mathrm{K}_{232}, \mathrm{~K}_{270}, \Delta \mathrm{K}$, OSI induction time did not exceed the maximum limits set by the International Olive Council (IOC) during the entire period. However, the content of ethyl esters increased with storage time and it is in relation with the shelf life. The International Olive Council (IOC) establishes the limits in the content of ethyl esters $\leq 35 \mathrm{ppm}$. The Coratina oil ceased to be extra virgin quality after 6 months of storage due to its content of ethyl esters (46 ppm), and the Arbequina oil after 9 months (52 ppm).

Taking into consideration their content of ethyl esters, both the Arbequina and Coratina oils showed a very short shelf life less than six months. The determination of ethyl ester content proved to be a sensitive method for determining the loss of quality of extra virgin olive oils.
\end{abstract}

Keywords: Extra virgin olive oil, shelf life, ethyl esters

\section{Introduction}

Morelló et al. (2004) studied the changes undergone extra virgin Arbequina oil during storage for 12 months. Although this paper included different analysis for determining the variation of certain minor components, the only stability analysis conducted consisted in determining the OSI times utilizing a Rancimat equipment set at $120^{\circ} \mathrm{C}$. Gómez-Alonso et al. (2007) studied the evolution of these minor components and the oxidation indexes in seven samples of virgin olive oil stored during 21 months at room temperature and in the dark. It was found that the peroxide index, K232 and K270 increased linearly over time (although never surpassing the limits set by the IOC). Del Caro et al. (2006) studied the influence of storage (in the light and in the dark), during 16 months, on the components of extra virgin olive oil (Bosana $c v$ ) and on the peroxide index, K232 and K270. During this period, the oxidation indexes did not exceed the limits set by the IOC.

Generally, extra virgin olive oil has a relatively long shelf life of 12-18 months of storage in bottles at room temperature, that means that oil produced in a given year may still be commercialized up until the next olive harvest. From a physicochemical viewpoint, the study of shelf life is generally based on determining acidity, peroxide index, and ultraviolet absorption.

Fatty acids methyl esters and ethyl esters are components of edible vegetable oils extracted form raw materials in bad conditions, therefore, should not be present in extra virgin olive oils (Gomez-Coca et al., 2012; Jabeur et al., 2015). Methanol and ethanol should first be formed in the system, possible through fermentation of the carbohydrates in the olives. Then, a transesterification of the triglycerides or esterification of the free fatty acids with these alcohols takes place. As a consequence, the presence of these esters in extra virgin olive oil indicates a poor treatment of the olives, which led to their fermentation.

If upon their elaboration, the virgin olive oils contain free methanol and ethanol, these will gradually esterify with the free fatty acids leading to the corresponding esters. As this process is relatively slow, an increase of the alkyl ester content and decrease of the free alcohols should take place during storage.

Among the quality requirements for extra virgin olive oils, the norm of the International Olive Council (IOC) 
2015, establishes the limits in the content of ethyl esters: $\leq 35$ ppm for the 2014/2015 and 2015/2016 crop years.

Waxes have a fundamental role in protecting the fruit from microorganisms attack and also from the point of view of the regulation of moisture in the fruit. This content in the fruit is determined by factors including agro-climatic as well as the variety of olives in others. However, the total wax content and its oil profile is affected by the extraction method used. The olive pomace oils, which are extracted with solvent, have a higher content compared to olive oils extracted by thermo-mixing. Moreover, the wax content increases during storage, although the reason for their formation has not yet been fully explained. The IOC establishes a limit for the content of waxes, so it is possible to consider it as a quality parameter as a tool for distinguishing between olive oil and olive-pomace oil and as a quality parameter for extra virgin olive oils enabling the detection of fraudulent mixtures of extra virgin olive oils with lower quality oils.

Olive oil has antioxidants such as tocopherols and polyphenols which protect it from oxidation. The $\alpha$-tocopherol represented more than $90 \%$ of total tocopherols. However, $\alpha$-tocopherol is the least protects oils from thermo-oxidation (Barrera-Arellano et al., 2002). Thus, the polyphenol content is extremely important because it largely polyphenols slow oil oxidation phenomena. Antioxidants in contact with air oxygen are degraded and therefore is of interest to study its evolution over time. To compare the oxidative stability of rancidity accelerated methods are the OSI and Rancimat method is used. Therefore, if there is a variation of the antioxidants present in the oil induction times determined by these methods should change.

The purpose of this study was to determine the shelf life based on different chemical parameters of extra virgin olive oils cv. Arbequina and Coratina, made in Uruguay and selected by their differences in antioxidant content.

\section{Materials and Methods}

\subsection{Samples}

Extra virgin olive oils of the Arbequina and Coratina varieties, were extracted used an Abencor laboratory oil mill (Comercial Abengoa S. A., Sevilla, Spain) kneading the olive paste at $30{ }^{\circ} \mathrm{C}$ during 30 minutes. The analyzer consisted of three basic elements: a hammer mill a thermomixer and a pulp centrifuge.

\subsection{Shelf Life Tests}

Samples were stored in $100 \mathrm{~mL}$ capped amber glass bottles, in an oven at $30 \pm 1{ }^{\circ} \mathrm{C}$ (usual summer temperature in Uruguay). Every month or every 3 months (as indicated) one bottle was removed from the oven and the oil analyzed.

\subsection{Analytical Techniques}

Peroxide Index: AOCS method Cd 8b-90. The weighed samples were dissolved in acetic acid-isooctane (3:2). Then saturated potassium iodide solution is added and left in the dark for 1 minute. Once this time elapsed was added $30 \mathrm{~mL}$ water and titrated with $0.1 \mathrm{~N}$ sodium thiosulphate using starch indicator as.

Ultraviolet Absorption (K232 and K270): AOCS method CH 5-91. The previously weighed samples were dissolved in isooctane. Subsequently, its absorbance was determined at wavelengths of $232 \mathrm{~nm}$ and $270 \mathrm{~nm}$ in a Shimadzu, Mini-UV 1240 model.

Polyphenol Content: method IOC/T.20/Doc. no. 29, "Determining olive oil biophenols through HPLC". Polyphenols present in the sample were extracted in a mixture of MeOH-water (80:20) with added syringic acid as internal standard. Polyphenols were determined on a Shimadzu HPLC, Model 20A, using a Phenomenex C18 column with a particle size of $5 \mu \mathrm{m}, 250 \mathrm{~mm}$ long and $4.6 \mathrm{~mm}$ diameter. For elution of polyphenols the following solvents were used: methanol, acetonitrile and phosphoric acid $0.2 \%$-water. Quantification of polyphenols was performed at $280 \mathrm{~nm}$.

Tocopherol content: according to published results by Andrikopoulus et al. (1991) determined through HPLC.

Tocopherols were determined in a Shimadzu model 20A HPLC equipped with Phenomenex C18 column with a particle size of $5 \mu \mathrm{m}, 250 \mathrm{~mm}$ long and $4.6 \mathrm{~mm}$ diameter. For this purpose, the following solvents were used: acetonitrile, methanol, 5\% acetic acid in water and isopropanol. Detection of tocopherols was performed by a fluorescence detector at the following wavelengths: $290 \mathrm{~nm}$ excitation and $330 \mathrm{~nm}$ emission.

Induction time (OSI): method AOCS Cd 12b-92. The oxidative stability was determined by OSI analysis in a Omnion OSI-8 instrument. The temperature of the heating block was maintained at $110^{\circ} \mathrm{C}$.

Ethyl esters content: method IOC/T.20/Doc. $\mathrm{n}^{\circ} .28$ "Determining the wax and methyl ester and ethyl esters of the fatty acids through a gas chromatography with capillary column". Methyl and ethyl esters were separated together with waxes by solid phase chromatography (SPE) using hexane-diethylether (99:1) as elution solvent. The extracts 
were analyzed in a gas chromatograph Shimadzu, Model 2010, using a column Restek, RTX-5MS. The methyl esters were quantified by addition of a solution of methyl ester heptadecanoic as internal standard and waxes by adding a solution palmityl palmitate.

All determinations were performed in duplicate.

\section{Results and Discussion}

Figure 1 shows the peroxide index evolution of the extra virgin olive oils of the Arbequina and Coratina varieties, over the 12 months of storage. The evolution of both oils was similar, although Arbequina oil showed greater to form peroxides than Coratina oil. This is justified by its polyphenol content (Figure 3). The maximum value allowed by the IOC 2015 Norm is 20 . After 12 months of storage these oils were far below that value. Therefore, according to this parameter, both oils were far from losing its quality extra virgin storage for one year. A similar behavior is found in the literature. (Gomez-Alonso et al., 2005; Del Caro et al., 2006; Vekiari et al., 2007; Lerma-Garcia et al., 2009; Krichene et al., 2010; Fadda et al., 2012)

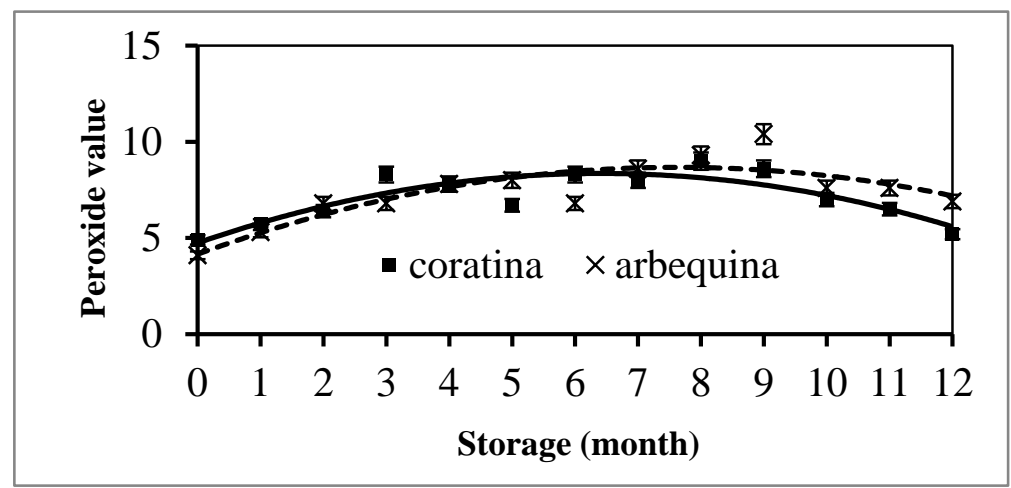

Figure 1. Variation of the Peroxide index of the Arbequina and Coratina oils over the 12 months of storage.

Figure 2 (where A corresponds to Arbequina and C to Coratina) shows the variation of the K232 and K270 indexes for both oils. During the 12 months period, the Coratina oil did not surpass the limits set by the IOC 2015 Norm: 2.5 for K232 and 0.22 for K270. Therefore, according to these parameters, this oil did not lose its quality extra virgin storage for one year. The Arbequina oil, however, surpassed both limits on the $12^{\text {th }}$ month. During the entire year of storage, the Arbequina oil always showed values slightly higher than those of the Coratina. A similar behavior is found in the literature. (Gomez-Alonso et al., 2005; Del Caro et al., 2006; Vekiari et al., 2007; Lerma-Garcia et al., 2009; Krichene et al., 2010; Fadda et al., 2012).

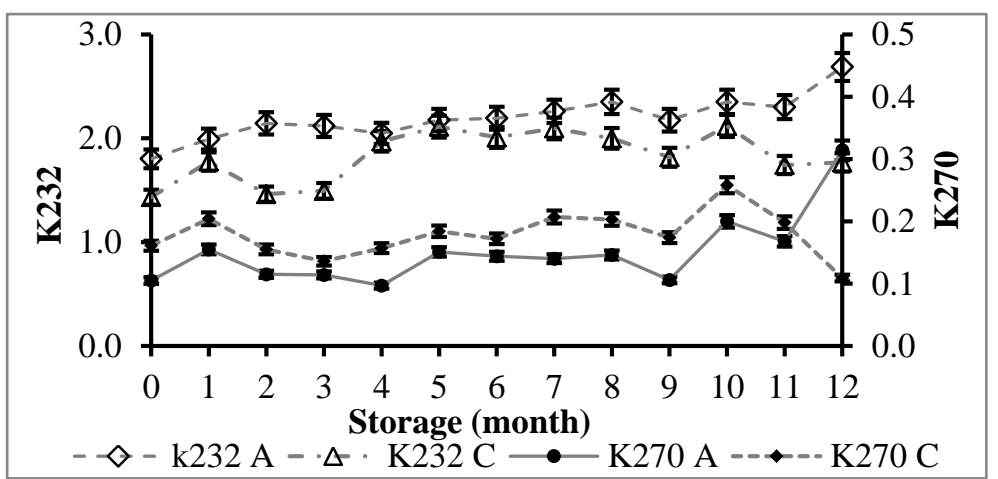

Figure 2. Variation of K232 and K270 for the Arbequina and Coratina oils over the 12 months of storage.

Wax esters are formed by the esterification of high molecular mass alcohols with fatty acids. The waxes most frequently found in olive oil are C40, C42, C44 and C46 (Samaniego-Sánchez et al., 2010). The wax ester content is used as a quality parameter and has also been used to detect adulteration. The 2015 IOC Norm established that the waxes content (not including the C40) of extra virgin and virgin olive oil must be $\leq 150 \mathrm{ppm}$ but if $\mathrm{C} 40$ is included, the oil will be considered ordinary virgin if that content is $\leq 250 \mathrm{ppm}$. The composition of waxes has also been used to differentiate varieties (Aragon et al., 2011).

Table 1 shows a variation in the wax content (as the addition of C40, C42, C44, C46 and not including C40) over the storage months for the Arbequina and Coratina oils. 
The wax content of both oils increased during storage. The explanation for this increase during storage of the oil is not known in the literature since no references to it found. While the content of wax $(\mathrm{C} 42+\mathrm{C} 44+\mathrm{C} 46)$ is a test of purity established by 2015 IOC Norm, because this increase could also be considered a quality test, because the IOC itself establishes a maximum of $150 \mathrm{ppm}$ for Extra virgin and virgin oils. However, neither of the oils lost their extra virgin quality, in spite of the increase in wax content over the storage period.

Table 1. Variation of the content of waxes (ppm) in the Arbequina and Coratina oils during the 12 months of storage.

\begin{tabular}{ccccc}
\hline & \multicolumn{2}{c}{ Arbequina waxes (ppm) } & \multicolumn{2}{c}{ Coratina waxes (ppm) } \\
\hline time (months) & With C40 & Without C40 & With C40 & Without C40 \\
\hline 0 & $78 \pm 5$ & $14 \pm 5$ & 0 & 0 \\
3 & $95 \pm 5$ & 0 & 0 & 0 \\
6 & $49 \pm 5$ & 0 & $5 \pm 5$ & 0 \\
9 & $152 \pm 5$ & $43 \pm 5$ & $12 \pm 5$ & $12 \pm 5$ \\
12 & $198 \pm 5$ & $96 \pm 8$ & $44 \pm 5$ & $44 \pm 5$ \\
\hline
\end{tabular}

The total polyphenol and tocopherols content variation (ppm) for both oils is shown in Figure 3 .

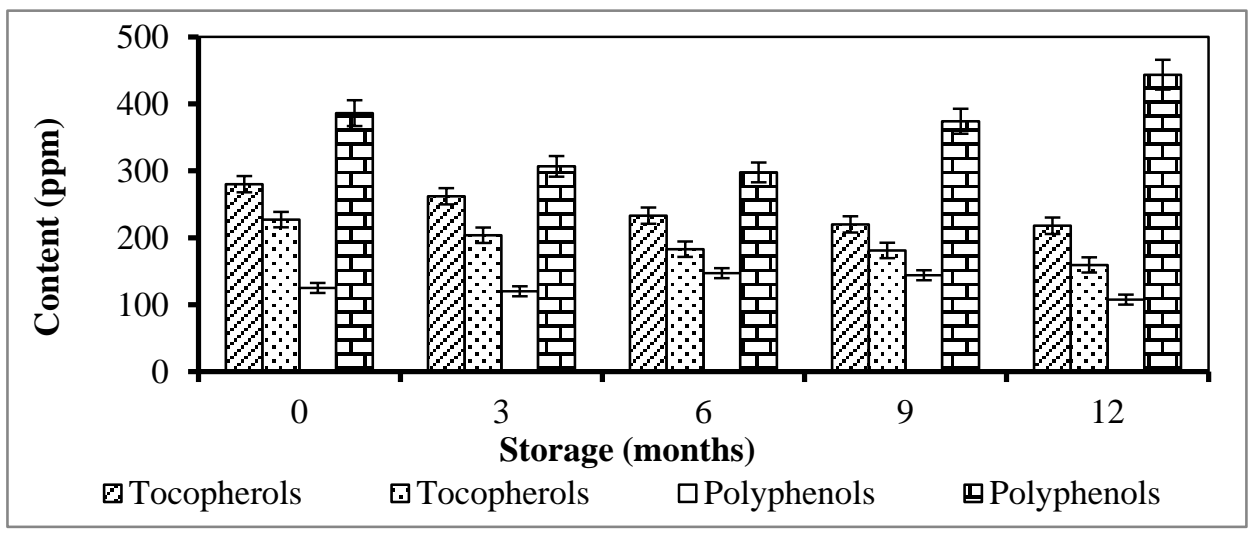

Figure 3. Variation of the content (ppm) of tocopherols and polyphenols in the Arbequina (A) and Coratina (C) oils during the 12 months of storage.

Over the 12 months storage period loss of tocopherols in both oils was statistically significant. Regarding decreased tocopherols during storage a similar behavior was found in the literature. (Morello et al., 2004; Gomez-Alonso et al., 2005; Del Caro et al., 2006; Lerma-Garcia et al., 2009; Fadda et al., 2012)

The polyphenols content of Arbequina oil was much lower than the Coratina, although its tocophenol content was slightly higher. From the point of view of their oxidative stability, polyphenols are the most important antioxidants of virgin olive oil. (Gutierrez et al., 2001; Carrasco-Pancorbo et al., 2005; Franco et al., 2014), Thus, Arbequina oil was less protected against oxidation than Coratina oil and was more prone to oxidation.

The polyphenol content Coratina oil showed a decrease and then an increase during storage; in oil Arbequina, that content first increased and then decreased. These variations are not easy to explain because modifications phenol content during storage of extra-virgin oil are complex. The main effects tested in the phenolic fraction during oil storage have been hydrolysis of secoiridoids and oxidation of some phenolic molecules.

During the storage of virgin olive oil hydrolitic mechanisms may be involved in the release of simple phenolics such as hydroxytyrosol and tyrosol from the more complex secoiridoids (Gutierrez Gonzalez Quijano et al, 1977). According to Krichene et al, (2010) the content of the simple phenols hydroxytyrosol and tyrosol increased in the initial stage of storage (ap. 16-20 weeks) as a result of phenolic aglycon hydrolysis. After this initial increase a clear decrease of hydroxytyrosol was observed probably due to its decomposition acting as an antioxidant. The concentration of the hydroxytyrosol measured at a particular time would therefore be the sum of its formation from the decomposition of its secoiridoid derivatives and its decomposition due to its role as antioxidant. The decrease in the complex phenols must be largely due to a lack of stability of these secoiridoid compounds. A similar behavior found Lozano-Sánchez et al. (2013).

Figure 4 shows the evolution of the induction times (OSI) for both oils during storage. OSI times for the Arbequina oil were considerably lower than for the Coratina. This is a consequence of their respective polyphenols content, according to Franco et al. (2014) that found positive correlation between total phenolic 
compounds and antioxidant capacity. Gutierrez et al. (2001) also demonstrate the contribution of polyphenols to virgin olive oil stability (measured as Rancimat induction tieme). OSI time did not evolve during storage because neither significant changes were observed in content of antioxidants. OSI time decrease with storage times are also reported in the literature. (Del Caro et al., 2006; Lerma-Garcia et al., 2009)

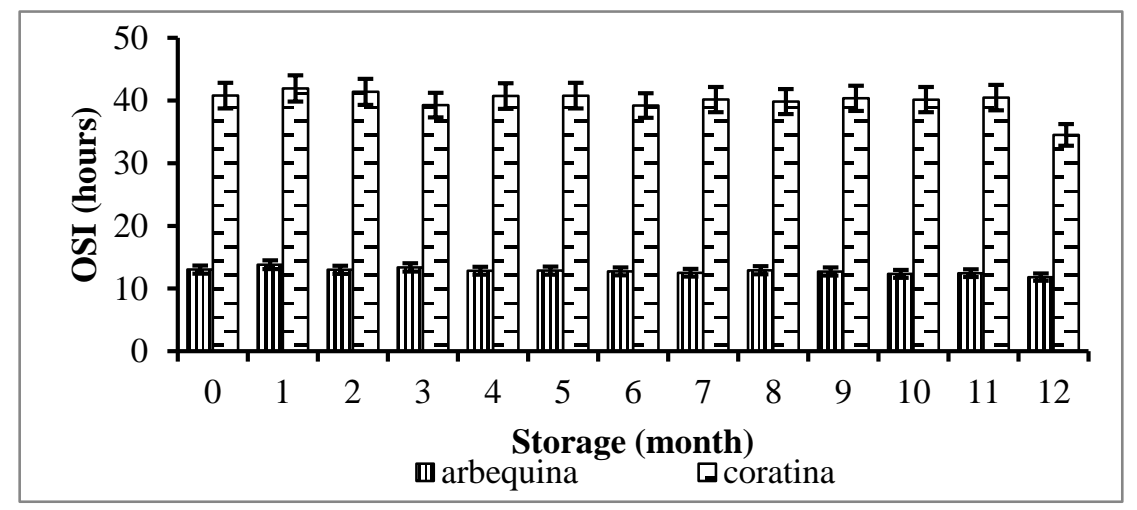

Figure 4. Variation of the OSI times (in hours) for the Arbequina and Coratina oils over the 12 months of storage.

The formation of ethyl and methyl esters in the oil has its origin in the esterification of free methanol and ethanol (possibly formed by fermentations of the olives, prior to oil extraction) with the free fatty acids (acidity). Bendini et al. (2009) related the ethyl fatty esters content of a number of samples with its sensory classification, together with the content of water and ethanol. When ethyl fatty esters are present at a certain concentration, the use of olive fruits with fermentative alteration becomes evident (Pérez-Camino et al., 2002). Gomez-Coca et al. (2012) studied the presence of fatty acid alkyl esters (FAAEs) of Spanish varietal extra virgin olive oils (bought in local markets). Ethyl esters content reached to $42 \mathrm{ppm}$ values. They also concluded that the content of ethyl esters and organoleptic data are complementary criteria when classifying olive oils and must be utilized as such. Fermentative defects are reflected in very high concentrations of FAAEs, whereas other kinds of defects, such as oxidative ones and frozen olives, do not produce FAAEs. Both kinds of attributes are detectable during the organoleptic assessment. In contrast, non-fermentative defects, do not affect the FAAEs classification criterion, but they are evidenced during the organoleptic evaluation. Figure 5 shows the variation of ethyl ester content (ppm) over the months of storage. The maximum allowed by the IOC 2015 Norm is $35 \mathrm{ppm}$. As a consequence, the Coratina oil ceased to be extra virgin quality at 6 months of storage, and the Arbequina at 9 months. As a consequence, the shelf life of both oils lasted about half a year (labeling usually indicates it must be consumed "before one year"). On the other hand, after 9 months of storage there was a significant acceleration in the formation of ethyl esters in both oils; the reason for this is unknown.

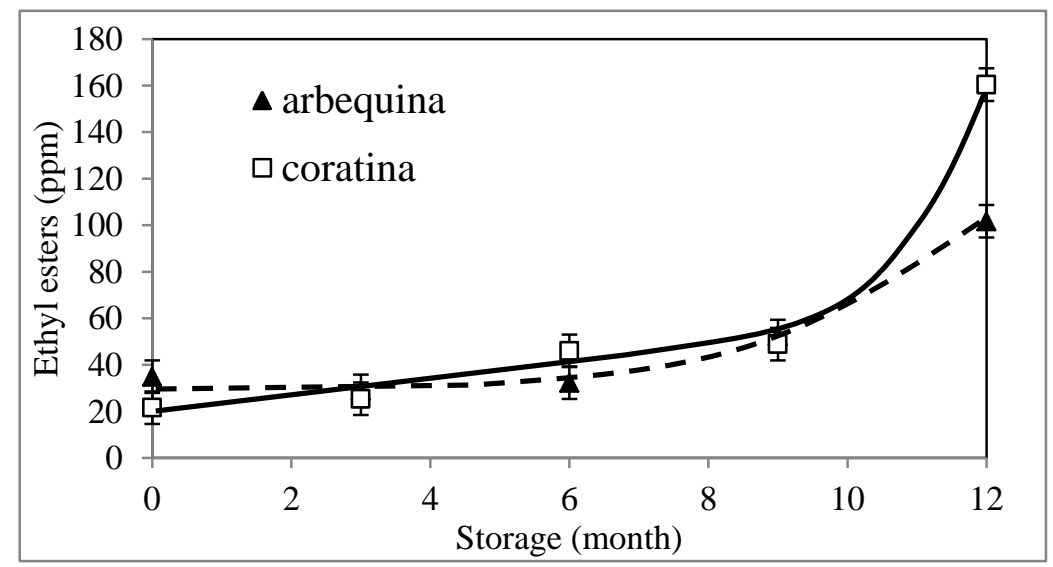

Figure 5. Variation in the content of ethyl esters (ppm) of the Arbequina and Coratina oils during the 12 months of storage.

At 6 months of storage, for both oils, all the legal quality parameters met the limits set by the 2015 IOC Norm, except the ethyl ester content, as it exceeded the legal limits. In the period of one year, the other quality 
parameters determined (peroxides index and ultraviolet absorbance) did not exceed the limits set by the IOC. Therefore, according to its FAEEs content both oils lost their quality extra virgin within 6 months. As a consequence, the ethyl esters content behaves as a sensitive parameter with regards to the shelf life of extra virgin olive oils.

\section{Conclusions}

In general, all parameters related to quality deterioration requires the IOC (peroxides index, ultraviolet absorbance to, ethyl esters content, phenol content) underwent significant variations during storage. However, according to the index values of peroxides, both oils were far from losing its quality extra virgin for one year storage. According to the values of ultraviolet absorbance, oil Coratina not lost its quality extra virgin for a year storage although oil Arbequina exceeded the limits set by the IOC at 12 months. Instead, the content of ethyl esters of both oils exceeded the limit set by the IOC, at about 6 months of storage. The content of ethyl esters is a sensitive parameter for determining the quality of extra virgin olive oil and for determining its shelf life. Using this parameter, both the Arbequina and Coratina olive oils showed a very short shelf life: under 6 months. However, they should carry out studies with other varieties of olives to draw more general conclusions about it.

Moreover, it would be important to relate the content of ethyl esters with the possible occurrence of defects in sensory oil.

\section{References}

Andrikopoulos, N. K., Brueschweiler, H., Felber, H., \& Taeschler Ch. (1991). HPLC analysis of phenolic antioxidants, tocopherols and triglycerides. J. Am. Oil Chem. Soc., 68, 359-364. http://dx.doi.org/10.1007/BF02663750

AOCS. (1990). Official Methods and Recommended Practices of the American Oil Chemists' Society. (4th ed.). Champaign, USA.

Aragon, A., Toledano, R. M., Cortes, J. M., Villen, J., \& Vazquez, A. (2011). Wax ester composition of onovarietal olive oils from Designation of Origin (DO) "Campos de Hellin". Food Chem, 129, 71-76. http://dx.doi.org/10.1016/j.foodchem.2011.04.021

Barrera-Arellano, D., Ruiz-Mendez, V., Velazco, J., Marquez-Ruiz, G., \& Dobarganes, C. (2002). Loss of tocopherols and formation of degradation compounds at frying temperatures in oils differing in degree of unsaturation and natural antioxidant content. J. Sci. Food Agric., 82, 1696-1702. http://dx.doi.org/10.1002/jsfa.1245

Bendini, A., Cerretani, L., Valli, E., Lercker, G., \& Mazzini, C. (2009). Application of analytical methods to determine mildly deodorized olive oils in commercial extra virgin olive oils. Industrial Alimentations, 48, 46-51.

Carrasco-Pancorbo, A., Cerretani, L., Bendini, A., Segura-Carretero, A., Del Carlo, M., Gallina-Toschi, T., Lercker, G., Compagnone, D., \& Fernandez-Gutierrez, A. (2005). Evaluation of the Antioxidant Capacity of Individual Phenolic Compounds in Virgin Olive Oil. J. Agric. Food Chem. 53, 8918-8925. http://dx.doi.org/10.1021/jf0515680

COI (Consejo Oleícola Internacional). (2015). Chemistry/Testing Methods/Chemical testing methods, http://www.internationaloliveoil.org/.

Del Caro, A., Vacca, V., Poiana, M., Fenu, P., \& Piga, A. (2006). Influence of technology, storage and exposure on componentes of extra virgin olive oil (Bosana $c v$ ) from whole and de-stoned fruits. Food Chem., 98, 311-316. http://dx.doi.org/10.1016/j.foodchem.2005.05.075

Fadda, C., Del Caro, A., Sanguinetti, A. M., Urgeghe, P. P., Vacca, V., Arca, P. P., \& Piga, A. (2012). Changes during storage of quality parameters and in vitro antioxidant activity of extra virgin monovarietal oils obtained with two extraction technologies. Food Chem, 134, 1542-1548. http://dx.doi.org/10.1016/j.foodchem.2012.03.076

Franco, M. N., Galeano-Díaz, T., Sanchez, J., De Miguel, C., \& Martin-Vertedor, D. (2014). Antioxidant capacity of the phenolic fraction and its effect on the oxidative stability of olive oil varieties grown in the southwest of Spain. Grasas y Aceites, 65(1), e004. doi: http://dx.doi.org/10.3989/gya.051513

Gómez-Alonso, S., Mancebo-Campos, V., Salvador, M. D., \& Fregapane, G. (2007). Evolution of major and minor componentes and oxidation índices of virgin olive oil during 21 months storage at room temperature. Food Chem., 100, 36-42. http://dx.doi.org/10.1016/j.foodchem.2005.09.006 
Gómez-Coca, R. B., Moreda, W., \& Pérez-Camino, M. C. (2012). Fatty acid alkyl esters presence in olive oil vs. organoleptic assesment. Food Chem., 135, 1205-1209. http://dx.doi.org/10.1016/j.foodchem.2012.05.053

Gutierrez, F., Arnaud, T., \& Garrido, A. (2001). Contribution of polyphenols to the oxidative stability of virgin olive oil. J. Sci. Food Agric., 81, 1463-1470. http://dx.doi.org/10.1002/jsfa.958

Gutierrez Gonzalez-Quijano, R, Janer del Valle, C., Janer del Valle, M. I., Gutierrez-Rosales, F., \& Vazquez-Roncero, A. (1977). Relacion entre los polifenoles y la calidad y estabilidad del aceite de olive virgin. Grasas y Aceites, 28, 101-106.

Jabeur, H., Zribi, A., Abdelhedi, R., \& Bouaziz, M. (2015). Effect of olive storage conditions on Chemlali olive oil quality and the effective role of fatty acids alkyl esters in checking olive oils authenticity. Food Chem., 169, 289-296. http://dx.doi.org/10.1016/j.foodchem.2014.07.118

Krichene, D., Allalout, A., Mancabeo-Campos, V., Salvador, M. D., Zarrouk, M., \& Fregapane, G. (2010). Stability of virgin olive oil and behavior of its natural antioxidants under medium temperature accelerated storage conditions. Food Chem., 121, 171-177. http://dx.doi.org/10.1016/j.foodchem.2009.12.026

Lerma-Garcia, M. J., Simo-Alfonso, E. F., Chiavaro, E., Bendini, A., Lercker, G., \& Cerretani, L. (2009). Study of chemical changes produced in virgin olive oils with different phenolic contents during an accelerated storage treatment. J. Agric. Food Chem. 57, 7834-7840. http://dx.doi.org/10.1021/jf901346n

Lozano-Sanchez, J., Bendini, A., Quirantes-Piné, R., Cerretani, L., Segura-Carretero, A., Fernandez-Gutierrez, A. (2013). Monitoring the bioactive compounds status of extra-virgin olive oil and storage by-products over the shelf life. Food Control, 30, 606-615. http://dx.doi.org/10.1016/j.foodcont.2012.06.036

Morelló, J. R., Motilva, M. J., Tovar, M. J. \& Romero, M. P. (2004). Changes in commercial virgin olive oil (cv Arbequina) during storage, with special emphasis on the phenolic fraction. Food Chem., 85, 357-364. http://dx.doi.org/10.1016/j.foodchem.2003.07.012

Pérez-Camino, M. C., Moreda, W., Mateos, R., \& Cert, A. (2002). Determination of esters of fatty acids with low molecular weight alcohols in olive oils. J. Agric.Food Chem., 50, 4721-4725. http://dx.doi.org/10.1021/jf025542+

Samaniego-Sanchez, C., Quesada-Granados, J. J., Lopez-Garcia de la Serrana, H., Lopez-Martinez, M. C. (2010). $\beta$-carotene, squalene and waxes determined by chromatographic method in picual extra virgin olive oil obtained by a new cold extraction system. J. Food Comp. Anal., 23, 671-676. http://dx.doi.org/10.1016/j.jfca.2010.03.010

Vekiari, S. A., Papadopoulou, P., \& Kiritsakis, A. (2007). Effects of processing methods and commercial storage conditions on the extra virgin olive oil quality indexes. Grasas y Aceites, 58(3), 237-242. http://dx.doi.org/10.3989/gya.2007.v58.i3.178

\section{Copyrights}

Copyright for this article is retained by the author(s), with first publication rights granted to the journal.

This is an open-access article distributed under the terms and conditions of the Creative Commons Attribution license (http://creativecommons.org/licenses/by/4.0/). 